\title{
Russia Revisited; Research Reviews: Faces, Hearts and Minds; of Multiple Interest
}

\author{
Nancy L. Segal \\ Department of Psychology, California State University, USA
}

\begin{abstract}
T:
win researchers from Russia have announced new opportunities for research collaboration at the Psychological Institute of the Russian Academy of Education, in Moscow. Members of the laboratory are also establishing Moscow's first Psychological Twins counseling room to facilitate practical activities, such as parental advisement and teacher training. Reference is also made to the work of twin researcher, Bronson Price, who spent several years at the Medico-Genetical Research Institute in Moscow. His papers are available at the library of the American Philosophical Society, in Philadelphia. Brief reviews of twin studies involving facial asymmetry and parental favoritism, social relationships and disputed memories are also presented. The article concludes with a look at several twin-related human interest items.
\end{abstract}

\section{Russia Revisited}

In an earlier issue of Twin Research, I presented a tribute to Russian twin researcher, Dr. Inna V. RavichShcherbo (Segal \& Senina, 2002). In that same review, I surveyed the history of Russian twin studies, namely their progress in the 1920s and 1930s, their disappearance through the early 1960 s and their reemergence in the late 1960s. This article continues to track the growth and development of twinrelated research projects and applied activities in Russia.

It is a pleasure to introduce three individuals - Sergey Malykh, Natalia Klipinina and Alina Siburina - who are continuing Dr. Ravich-Shcherbo's wonderful work. Here is what they have to say (edited slightly):

\section{Dear Colleagues!}

The developmental behavior genetics laboratory of the Psychological Institute of the Russian Academy of Education, in Moscow (http://www.pirao.ru) offers opportunities for collaboration. Among the employees of the laboratory are specialists in general, developmental, clinical and neurological psychology. The head of the laboratory is S. B. Malykh, PhD. Since 1972, our laboratory has been investigating questions concerning environmental and genetic effects on individual differences in psychological and psychophysiological development. In conducting these investigations the twin study method is commonly used. As a result, the Moscow Twins Registry was formed and considerable information concerning twins' unique development has accumulated. In recent times, employees of the laboratory (Malykh S., Egorova M., P'ynkova S., Siburina A., Gindina E., Klipinina N. and Barsky Ph.) have focused their attention on practical work concerning unusual features of interaction among members of twins' families and the specifics of twins' development. In 2000, the site (http://www.twinsclub.ru) was created to throw light on numerous twins' problems and to help both parents and twins in many ways. Within the project ("Generation.ru”), the forum devoted to twins' special issues is conducted (http://www.parent.fio.ru). In this connection, employees of the laboratory are planning to establish a Psychological Twins counseling room, which will be the first ever in Moscow.

Specific activities will be as follows:

- individual and family counseling with twins, higher-order multiples and their parents

- group training with twins and their parents

- practical work with teachers, educators and parents

- publication of various educational supplies and booklets for twins' families

- collaboration with foreign colleagues.
Physicians, physiologists, pediatricians and twins' parents will be participating in this project together with psychologists. We would be grateful to you for making colleagues aware of these collaborative opportunities. We would also thankfully accept any educational supplies on twins' unique problems, as well as your advice and suggestions. On our part, we would willingly share our own experience concerning areas of common interest.

Please send us email at info@twinsclub.ru

With best regards,

Sergey Malykh,

Natalia Klipinina and Alina Siburina.

I would urge interested individuals to pursue this opportunity. My participation in the Moscow Summer School series in 2001 was a fascinating experience. I am very pleased that twin research in Russia is continuing to attract the attention it deserves.

\section{Bronson Price}

In my earlier article with Senina, I mentioned investigator Bronson Price, famous for his 1950 and 1978 papers

Address for correspondence: Nancy L. Segal, Department of Psychology, California State University, Fullerton, CA 92834 USA. Email: nsegal@fullerton.edu 
on prenatal influences on $\mathrm{MZ}$ twin development. I noted that Price had spent time in Moscow as a fellow of the Social Science Research Council:

There he became a close colleague of Herman J. Müller, geneticist and senior scientist at the MedicoGenetical Research Institute in Moscow from 1933-1936. Price produced a paper, 'USSR notes' (Price, 1937), copyrighted, but unpublished ... Price's precious notes and memoirs would provide an informative take on the nature of twin research and other activities during those times (p. 55).

In the weeks following publication of my article, I attempted to locate some of Price's papers. I did this partly out of curiosity, but also as a favor to Dr. Ravich-Shcherbo who asked the following question in one of her notes to me: "He [Price] researched giftedness using the twin method and also lead the seminars. Could it be the same
Bronson Price who is mentioned in your book on page 319 and in other works of psychogenetics?” (p. 55). I was unable to uncover promising leads and eventually turned to other things. Then, last month, while browsing online holdings of the American Philosophical Society's (APS) library, in Philadelphia, I encountered a surprise treasure trove: "Bronson Price Papers, 1926-1978 (4 linear feet)". I couldn't believe it! The following materials occupy the four feet of space:

- correspondence: 1926-1978 (1 foot)

- twin articles: 1942-1976 (1 foot)

- twin bibliography: ca. 1940s1970s (2 feet)

- photographs: 1978 (.1 foot)

Considerable detail concerning the contents of these files is available at the library's website (http://www amphilsoc/library/browser/p/pricebronson.htm). I suspect that some of the most fascinating materials will be found among the correspondence between Price and Müller with whom Price developed a close professional and personal relationship. These letters should offer insights into Price's experiences in Moscow and the genesis of his ideas on twins, fertility, eugenics and other topics. However, Price corresponded with many well-known individuals interested in twins, namely Kurt Benirschke, R.A. Fisher, David Rife, David Rosenthal, Daniel G. Freedman and Amram Scheinfeld. I have requested selected materials from this library and will review them in a later issue of Twin Research.

There is a great deal of interesting material stored at the APS library. A tour of their holdings is well worth doing.

\section{Research Reviews: Faces, Hearts and Minds}

\section{Do Parents Show Favoritism for Their Symmetric Children? (A Twin Study)}

I want to preface this summary by saying that this work is unpublished, but I have heard it presented twice. The first time it was delivered by the investigator, Dr. Linda Mealey, at the June, 2002 Human Behavior and Evolution Society meeting at Rutgers University, in New Brunswick, NJ. The second time it was delivered by me at the August, 2002 meeting of the International Society for Human Ethology (ISHE), in Montreal, Canada. The second occasion was not a happy one - my good friend and colleague, Linda Mealey, had just been diagnosed with liver cancer and was unable to attend the sessions. I was proud to present this work, but saddened by the reason why.

Fluctuating asymmetry (FA) refers to departure of the face and body from perfect symmetry or consistency (Gangestad \& Thornhill, 1996). It has been of considerable interest to evolu- tionary psychologists as an index of developmental instability - it is thought to be linked to a range of stressful events to which some people may be more susceptible. People with greater FA have been judged to be less attractive and tend to have fewer sexual partners than individuals judged to be of higher FA. However, only an MZ twin study can eliminate genetic differences (e.g., skin quality, skin tone) as confounding factors in making these assessments - Linda Mealey's investigation is the only one to use twins in this creative way.

The abstract of her study is reprinted below from the ISHE conference program booklet. A summary of findings and their implications follow:

In a previously published study (Mealey et al., 1999), we were able to demonstrate that among pairs of identical twins, the more symmetric twin was consistently rated as the more attractive, and that the magnitude of the difference in perceived attractiveness of co-twin pairs was directly related to the magnitude of the difference in their symmetry. More recently,

\begin{abstract}
Mealey (2001) has suggested that the study of monozygotic (but not truly "identical") twins might provide a new method for mapping experiential differences onto phenotypic differences and differences in life history strategy. As an initial attempt to use this methodology, we recontacted twins from the symmetry study and asked them to complete questionnaires about their perception of their parents' parenting style. We suspected that the more symmetric twin of a pair would likely have received preferential treatment by parents, and would thus report more favorable perceptions of their experience than would their less symmetric co-twin. We also tested the same prediction using the more standard methodology, by ignoring twinship status and correlating individuals' symmetry with individuals' parenting style.
\end{abstract}

Twenty-five MZ twin pairs (11 male pairs and 14 female pairs) completed the Parental Bonding Instrument (PBI), a 25-item, forced choice (almost always; frequently; not very often; almost never) questionnaire (Parker et al., 1979). The aim was to obtain twins' perceptions of 
their treatment by mothers and fathers during their first 16 years of life. Sample items were: "was affectionate to me", "tended to baby me", and "made me feel I wasn't wanted". All twins had been previously rated for facial asymmetry and diagnosed for zygosity by blood group analysis. The central question was: did more symmetrical co-twins perceive preferential treatment from their parents?

The data analysis revealed no significant patterns. The sole exception was question 16 ("made me feel I wasn't wanted"), but the effect was in the reverse direction to what was predicted (i.e., less symmetric twins felt more wanted by their parents than did their more symmetric co-twins). Several interpretations were suggested, but it may be that parents do not discriminate between twins on the basis of their relative facial symmetry. It is also possible that childhood FA differs from later FA, affected by significant growth periods such as adolescence. With regard to question 16 , it could be that when parents have adequate resources, they invest additional care in less healthy twins. This would imply that when resources are scarce, it would make better "genetic sense" to invest resources in healthier twins.

Hopefully, additional efforts in this interesting area will be forthcoming. I am very saddened to say that on the very day I returned the proofs for this article, Dr Linda Mealey passed away. Her untimely death is a loss to everyone who knew her — friends, colleagues, and family. Please direct cards and letters to:

Mealey Family
c/o St. John's University
Department of Psychology
Collegeville, MN 56321

\section{Twin Relationships in Old Age}

Twin relations in young twins have been studied far more frequently than twin relations at the upper end of the life span. It was, therefore, a pleasure to read a recent study by Franz J. Neyer, of Humboldt University, in Berlin, Germany (Neyer, 2002). The sample included $133 \mathrm{MZ}$ twin pairs and 60 same-sex DZ twin pairs, with mean ages in the early 70 s. (Age ranges were not provided for the full sample or for the sex x zygosity groupings.) Twins visited the university to complete an extensive series of interviews and questionnaires concerning their intra-twin relations. These surveys were organized into three main categories: biography, social network and twin relationship.

Many meaningful findings are reported in this paper. Primary among them are that, since adolescence (1) $\mathrm{MZ}$ twins lived closer to one another, and had more frequent contact, emotional closeness and social support than DZ twins; (2) Twin relationships for both types of twins showed more intense contact, intimacy, conflict and support than did each twins' relationship with their non-twin siblings and (3) $\mathrm{MZ}$ co-twins' higher attachment security and relationship satisfaction were independent of their contact frequency, while DZ co-twins' security and satisfaction were dependent on their degree of contact.

This study demonstrates that social relationships within older $\mathrm{MZ}$ and $\mathrm{DZ}$ twin pairs are qualitatively different. These findings remind us of the importance of specifying twin type in all discussions of twin findings.

\section{Twins' Disputed Memories}

One of the more intriguing studies I have recently come across concerns disputed memories (i.e., recollections for which people disagree over "ownership") (Sheen et al., 2001). The investigators justified their use of twin participants with reference to the following: they had anecdotally observed disputed memories among twins, twins' physical similarities allow for imagery confusion within sets, twins' physical similarities allow for imagery confusion among other people who might unknowingly implant false memories in the pair, twins' matched ages lead them to share many life history experiences and twins (especially MZ twins) tend to "assimilate their personalities" (p. 779).

A series of three linked experiments yielded a series of compelling findings: (1) zygosity and gender differences in number of cued disputed memories were not found; (2) disputed memories received higher recollective experience and sensory imagery ratings than nondisputed memories; and (3) disputed memory experience was more frequent among twins than among near-in-age siblings and friends.
I was intrigued by this report, yet found several aspects wanting. I summarized these points in a letter to the editor but, unfortunately, journal correspondence is not included in the journal, Memory and Cognition. My remarks are reproduced as follows:

It is disappointing that the procedures used for zygosity determination were not adequate, casting uncertainty over the monozygotic (MZ)-dizygotic (DZ) twin comparisons. Specifically, zygosity was assigned following an interview during which participants were "asked whether they were $\mathrm{MZ}$ or DZ twins” (p. 780). Many twins (and their parents) are uncertain, even wrong, as to twin type, mandating that this information be obtained via standard scientific methods (e.g., DNA analysis, serological studies or physical resemblance questionnaire) (see Segal, 2000). It is likely that most twins who did volunteer their twin type relied on number of placenta, but this would only have invited error. Specifically, it is a common misconception that one placenta indicates MZ twins and two placentae indicate DZ twins; rather, approximately one-third of $\mathrm{MZ}$ twins have separate placentae (associated with early zygotic division) and $42 \%$ of DZ twins have a single placenta (due to fusion from close implantation) (Bulmer, 1970). It was also the case that two twin pairs were assigned as MZ (presumably by the investigators), based on their similarity of appearance. (These pairs claimed that their zygosity had never been assessed, but they were raised to believe they were MZ.) This procedure was not explained, nor applied systematically across pairs. Occasional DZ twins look very much alike, even to the point of confusion by trained investigators, as I document in my book, Entwined Lives (Segal, 2000). Possible misclassification of twins, especially in a small sample ( $n$ = 20 pairs), renders results questionable. It was, for example, surprising that $\mathrm{MZ}$ twins did not experience more disputed memories than DZ twins, given their closer social relationship. Note that the numbers of MZ and DZ pairs studied were not provided in the text, although were retrievable from a table.

Gender differences in disputed memories did emerge in Experiment 2 when twins were asked directly (without cues) 
if they had experienced disputed memories with their co-twins. Here, female twins exceeded male twins. The investigators suggested that female twins may talk to each other more than male twins, an explanation that may be likely. They supported this interpretation with reference to Koch's (1966) study showing greater social compatibility among female than male pairs, and greater social withdrawal among male than female twin children. However, twins in Koch's study were age 5 to 6 years of age, while twins in the present study were 16 to 56 years of age. Thus, the two twin samples do not seem comparable.

\section{Of Multiple Interest}

\section{Twin Sculpture}

There is a twin sculpture gracing the entrance to a New York City row house, located at 328 East 51st Street (Gray, 2002). It is Mary Tonetti's recreation of Julia and Comfort Tiffany, twin children born to designer Louis Comfort Tiffany in 1887. The twin girls appear to be about 10 or 12 years of age. Their family never lived at that address; rather, the home belonged to actress Katharine Cornell, a friend of Tonetti's. It is estimated that the sculpture, installed at its present spot in 1965, was created in 1900. Apparently, Cornell had a particular fondness for this work and received it as a housewarming present from the sculptor's daughter, Anne.

The twins, Julia and Comfort, shared a close twin relationship even as they led separate lives. Julia worked in medical research, while Comfort was an artist. (Interestingly, Julia never received a college degree because her father disapproved of higher education for women.) The twins passed away in 1973 and 1974, respectively. I have never seen this sculpture, but it is only a short walk from the apartment where I stay during visits to New York. I look forward to seeing it during the next semester break.

\section{Olsen Twins}

Universal interest in twins is perhaps no more apparent than in the case of the Olsen twins, Ashley and MaryKate. These teenage twins, who launched their career in ABC's sitcom,
Full House, at age 9 months, are now 16 years old (New York Daily News, 2002). The twins, who claim to be DZ, are idolized by young girls everywhere. According to one web site (http://billboarddad. warnerbros.com/ cmp/aboutgirls.htm):

"While they appear to be identical twins they are fraternal - with Ashley, who is right-handed, born two minutes before southpaw Mary-Kate".

Given the twins' nearly matching faces and physiques and same eye color (blue-green), I was surprised to see so many confident claims that they are fraternal twins. I am certain that they are $M Z$ twins! In fact, I suspect that their identical appearance largely explains the fascination with which they are held by so many of their young admirers and why they have been so successful in business and entertainment. True, they stand two inches apart (see: htttp://www.expage. com/leopardgiv1828), but that is not atypical for some MZ twins who may differ physically due to prenatal stressors (Machin \& Still, 1996). A number of parents and colleagues I know also question the idea that the Olsen twins could be fraternal.

It seems that Ashley and Mary-Kate could best serve their teenage identical twin fans by scientifically confirming their twin type. There may well be twins who suspect they are identical, but "wish" to be fraternal, following the leads of their idols. Such twins may be fighting a natural inclination to behave similarly, purposely choosing different activities and friends when they would be more comfortable
Continued used of twin research methods to assess new hypotheses and predictions surrounding disputed memory will, hopefully, continue. This is exciting work that is amenable to varied interpretation by diverse theoretical frameworks.

sharing them. It is so important for twins and families to be certain of twin type - this information is relevant to twins' relative behavioral and physical development and disease predisposition. Of course, given the vagaries of genetic transmission, there remains a small chance that the Olsens are very look-alike fraternal twins.

I do not know if the Olsen twins' zygosity has been scientifically confirmed, but indications in the media are that it has not. I would be more than willing to arrange an appropriate test for Ashley and Mary-Kate when they are ready.

\section{Literature Searches}

Like most twin researchers, I am notified weekly of new scientific articles using twins as research participants or that describe new developmental aspects of twinship. Keywords entered in these searches are typically: twin, twins, twinning, multiples, and so forth. I have discovered some extremely valuable resources in this way. I have also amassed an expanding pile of irrelevant twin-related resources. Here is a brief sampling:

"Dielectric Morphology of Twin Domains in LaAlO3 Observed by a Scanning Microwave Microscope"

"Gem of Centaurus A Magnificant Spiral Galaxy in Centarus Could Almost be Milky Way Twin Were it Not for One"

"Twin Priming: A Proposed Mechanism for the Creation of Inversions in L1 Retrotransposition"

Interest in twins and twinning is more pervasive than we realize! 


\section{References}

Gangestad, S. W., \& Thornhill, R. (1996). The evolutionary psychology of extrapair sex: The role of fluctuating asymmetry. Evolution and Human Behavior, 18, 69-88.

Gray, C. (5 March, 2002). The Tiffany twins. New York Times.

Machin, G., \& Still, K. (1996). The twin-twin transfusion syndrome: Vascular anatomy of monochorionic placentas and their clinical outcomes. In L. G. Keith, E. Papiernik, D. M. Keith, \& B. Luke (Eds.) Multiple pregnancy: Epidemiology, gestation and perinatal outcome (pp. 367-394). New York: Parthenon.
Mealey, L. (200I). Kinship: The ties that binds (disciplines). In H. R. Holcomb, H.R. (Ed.), Conceptual challenges in evolutionary psychology: Innovative research strategies. Dordrecht, the Netherlands: Kluwer.

Mealey, L., Bridgstock, R., \& Townsend, G.C. (1999). Symmetry and perceived facial attractiveness: A monozygotic co-twin comparison. Journal of Personality and Social Psychology, 76, 157-165.

New York Daily News. (2002). Mary-Kate and Ashley Olsen, p. S-3.

Neyer, F. J. (2002). Twin relationships in old age: A developmental perspective. Journal of Social and Personal Relationships, 19, 155-178.
Parker, G., Tupling, H., \& Brown, L. (1979). A parental bonding instrument. British Journal of Medical Psychology, 52, I-10.

Segal, N.L. (2000). Entwined lives: Twins and what they tell us about human behavior. New York: Plume.

Segal, N. L., \& Senina, I. N. (2002). Russian twin studies: Colleagues, controversies, case studies and current events. Twin Research, 5, 53-64.

Sheen, M., Kemp, S., \& Rubin, D. (200I). Twins dispute memory ownership: A new false memory phenomenon. Memory and Cognition, 29, 779-788. 